\title{
THE INFLUENCE OF INTERNET TECHNOLOGY ON THE DEVELOPMENT OF TEACHING AND LEARNING METHODS FOR STUDENTS
}

\author{
Alvin Rizky Pratama1, Mita Yulianti Taufik ${ }^{2}$, Acep Hariyudin ${ }^{3}$ \\ ${ }^{1}$ IKIP Siliwangi \\ ${ }^{2}$ IKIP Siliwangi \\ ${ }^{3}$ IKIP Siliwangi \\ 11vinz_db@yahoo.com, ${ }^{2}$ mitayulianti@ rocketmail.com, ${ }^{3}$ haryacep@gmail.com
}

\begin{abstract}
The research titled the Influence of Internet Technology on The Development of Teaching And Learning Methods For Students is aimed to easier learning process at the class with studets. Information and communication technology are fenomenal and the beginning of the emergence of a web application is the internet. Internet which originated from research to defense and security as well as educational support tolls business evolved into a very influential. This is also encouraging to provide internet service facility. Students who have signed up to can do anything, including transaction log, learn, etc. with the technology services can solve the problems facing employes who leave in especially for those who work while studying or courses. Internet is very important to considered the problem learning and teaching. The purpose of the study is intended to obtain data and information on the effect to the use internet and browser for educational programs. The results of this study found that the role of information technology an education, in addition to helping students in learning also had a quite influentialrole for teachers, especially in the use of facilities to end rich teaching skills and guidance for the development of science and technology $\mathrm{n}$ order to strengthen in iprove human well - being.
\end{abstract}

Keywords: Internet, Technology, Learn, Educational

\section{INTRODUCTION}

Nowadays the development and progress of information technology is running very fast. Along with the development of information technology, data storage and shipping is getting better and better quality. Both individuals, institutions and governments participate in various efforts to take advantage of this information technology development. Even in the world of education in Indonesia,it is time for us to facilitate this information technology. Especially with the exixtence of school net programs or hot spot facilities in schools and other public places, all components of educational institutions are required to prepare themselves by preparing facilities, infrastructure to take advantage of technological developments that information. This information technology will provide added value in the learning process. This is related to the increasing need for information on science and technology not all of which are obtained in the school environment. Effective and efficient when utilizing technology.

Technology has been argued as having a positive impact on our way of thinking. Removed, Request, \& Original (2016), in his nationally bestselling book Everything Bad is Good for You, posited that technology is helping to make creation of learning program between strategy and solving of material project in the classroom. The situation,many education can improve to high quality.The results of technology have long been used in education. The discovery of paper,printing machines,radio,film, TV,computers and others was used for education.In essence 
these tools are not specifically made for educational purposes, but these tools can actually be utilized in the world of education.

In this global era more and more technological developments are difficult to use in various fields, one of which is in the world of education. Because technology does not escape the role of education that must be emphasized. Besides education is very important for us, so from that it is also the purposes of discussion about technological development in the world of education is so that students or readers can understand how the relationship between education and technology that all technology comes from education itself

Technological literacy, technological nimbleness is the ability for identification of a concrete problem and what specific tools you need for solving it. Speaking in appositive perspective,the impact of technology on education has become phenomenal.Using the internet and computers as an effective medium for building communication between schools, teachers,students and parents,educational instituions have been able to handle many things that were not previously handled easily because of geographical limitations or lack of adequate technology.Also the list of existing tools is thus big, that it's impossible to use all the elements at the same time. But what's the main part? School and teachers find that optimal combination, which let them give children the information effectively, also estimate them and rise up the productiveness of the teaching process (Geladze, 2015).

\section{Internet Technology}

Technology according to experts (Utami, 2018) stated that technology had actually existed before or humans had used technology. If humans in the past broke candlenuts with stones or picked fruit with poles, in fact they had used technology, namely simple technology. Regarding technology, (“Genrty_Educational_Technology-_A_Question_of_Meaning.pdf," n.d.) defines technology as the application of behavioral and natural sciences and other knowledge in a systematic and systemic manner to solve problems. Other experts, (Kast \& Rosenzweig, 2018) stated technology is the art of utilizing scientific knowledge. Whereas formulates clearer and more complete definition of technology, namely how to do something to meet human needs with the help of tools and intellect so as to prolong, strengthen or make more effective members of the body, the five senses and the human brain.

(Fernandez, 2009) technology has been known to humans since millions of years ago because of the urge to live a more comfortable, more prosperous and more prosperous life. So since the beginning of civilization there have actually been technologies, even though the term "technology" has not been used. The term "technology" comes from "techne" or the way and "logos" or knowledge. So technology can literally mean knowledge about ways. According to him, the definition of technology is a way of doing things to meet human needs with the help of reason and tools, so as to prolong, strengthen or make more effective members of the body, senses and the human brain. Rational leads and has the characteristics of efficiency in every field of human activity.

\section{Classroom Based Assessment}

(Wiliam, 2013), classroom based assessment is discussed to provide more details of the relationship between assessment and learning in classrooms.In the educational context, the term "assessment" is often associated with "testing" for most of the teachers, learners and other stakeholders . 
However, testing is only one element of assessment and it actually encompasses a wider range of factors from tests to dynamic and collaborative activities and tasks. Therefore, it is necessary to clarify the difference between assessment and testing before looking at the definition of classroom-based aassessment.

The development of information technology that is increasingly rapid in the era of globalization is now unavoidable influence on the world of education.Global demands require the world of education to always and constantly adjust technological developments towards efforts to improve the quality of education,especially adjusting the use of information and communication technology for the world of education,especially in the learning process.

\section{METHOD}

The development of the internet in the world of education has resulted in a distance learning system. With this system, a student no longer needs to go to school like a formal school. But enough to take the time to meet face to face with the lecturer or teacher through a computer monitor. Likewise students not only obtain information about knowledge through library books and even have to go to the library to obtain knowledge, but enough is in front of the monitor, the knowledge that will be sought is available. Even a teacher will easily search for teaching materials that are appropriate to his field and also a student can explore the knowledge gained by being supported by the ability to search for additional information beyond what is taught by the teacher. Likewise the community (student guardian, education board and school committee) can also provide input and control the school in choosing and using quality education books. There will be a change in the mindset and creativity of teachers and students and the community can develop rapidly, so that there is a more contextual thinking horizon and easier to digest the information entered. Even within the scope of education, it is time to form an information network .

\section{RESULTS AND DISCUSSION}

\section{Results}

\section{a) Google}

Besides functioning as a liaison, the internet also plays a role like a data bank. The upload and download system makes it easy for all internet users to continue to share and get information. In searching data, it is known as the search engine which is a site or program specificially designed as a document finder. The best and most popular search engine is google. This site can be used to search for any data on the internet network. If viewed from the world circle of education, the presence of the internet is the best vehicle to make it easier students to gain access to data and unlimited information about the material taught in the scope of schools or universities. However, it needs to be recognized, unlimited access then under certain conditions can have a negative effect. Especially if not accompanied by adequate supervision.

This one function of google is to help us know the current time (real time) in a city or country for various purposes,for example when going to make phone calls abroad.To check the time on google,you can just type 'time', so google will tell you the current time where you are.To find out time in another city or country,you can followed by the name of the city or destination country. 


\section{b) Facilitate Information Access}

With its function as a data, inevitably, internet media can be used by students to find data to supplement teaching materials at schooland on campus. In addition, information such as news is always updated so that internet users can always update the information they get practically. The information required to satisfy this need transcends document boundaries and is a culmination of the knowledge gleaned from documents examined during the search session (Belkin, 1984).However ,returning a ranked list of documents does not fit well with this model.The list restricts the interaction and general information seeking behavior of searchers; they are forced to examine search results individually.

Most web search interfaces present the searcher with little information with which to decide whether or not to view a retrieved document.Typically the only information shown is the document title, URL and short sentence fragments containing the query terms and a small number of fore and aft terms to afford context.These snippets are rarely full sentences, and often separated by ellipses.

The Methods sections should be brief, but they should include sufficient technical information to allow the experiments to be repeated by a qualified reader. Only new methods should be described in detail. Cite previously published procedures in References.

\section{CONCLUSION}

The Conclusion should contain the confirmation of the problem that has been analyzed in result and discussion section. The Conclusion should contain the confirmation of the problem that has been analyzed in result and discussion section. The Conclusion should contain the confirmation of the problem that has been analyzed in result and discussion section.

As a conclusion, we can seen that almost the students prefer to communication with people from various ethnic backgrounds, education, age can be done through the social networking site. This is particularly true among differences system or method to learn the material and education.

Based on the results of data analysis on the problems that the authors examine,namely the influence of the internet for education, it is concluded that:

1.The internet is more influential in the world of education because basically the internet is presented for educational purposes.

2.The internet brings a variety of influences, both positive and negative,towards educators and students.

3.It is better to use the internet more in positive terms.

\section{ACKNOWLEDGMENTS}

Finally,I would like to thank everybody who was important to the successful realizization of this article.The article is far from perfect,but it is expected that it will be useful not only for the writers, but also for the readers. We respect and thank to Mr. Acep and Mrs.Aseptiana for giving we an opportunity to do this assignment work and providing us all support and guidance which made the complete assignment on time. For this reason,constructive thoughtfull suggestion and critical welcomed.

\section{REFERENCES}

Fernandez, J. M. (2009). From Charity To Social Investments And Social Justice: A Study Of 
Philanthropic Institutions In Indonesia. Asian Transformations In Action: The Work Of The 2006/2007 Api Fellows, 26-35.

Geladze, D. (2015). Using The Internet And Computer Technologies In Learning/Teaching Process. Journal Of Education And Practice, 6(2), 67-69. Retrieved From Http://Iiste.Org/Journals/Index.Php/Jep/Article/View/19402\%5cnhttp://Iiste.Org/Journal s/Index.Php/Jep/Article/Viewfile/19402/19585

Genrty_Educational_Technology-_A_Question_Of_Meaning.Pdf. (N.D.).

Kast, F. E., \& Rosenzweig, J. E. (2018). General Systems Theory: Applications For Organization And Management. Academy Of Management Journal, 15(4), 447-465. Https://Doi.Org/10.5465/255141

Removed, A., Request, A. T., \& Original, O. F. (2016). Understanding Media And Culture : An Introduction To Mass Communication [ Author Removed At Request Of Original Publisher ].

Utami, I. S. (2018). The Effectiveness Of Blended Learning As An Instructional Model In Vocational High School. Journal Of Educational Science And Technology (Est), 4(1), 74. Https://Doi.Org/10.26858/Est.V4i1.4977

Wiliam, D. (2013). Assessment: The Bridge Between. Voices From The Middle, 21(2), 40. Retrieved From File:///D:/Semester 6/Off To Thesis/Vm0212assessment.Pdf 